\title{
Sodium Variable Conductance Heat Pipe for Radioisotope Stirling Systems
}

\author{
Calin Tarau ${ }^{1}$, William G. Anderson ${ }^{2}$, and Kara Walker ${ }^{3}$ \\ Advanced Cooling Technologies, Inc., Lancaster, PA 17601 U.S.A.
}

\begin{abstract}
In a Stirling radioisotope system, heat must continually be removed from the General Purpose Heat Source (GPHS) modules to maintain the modules and surrounding insulation at acceptable temperatures. Normally, the Stirling convertor provides this cooling. If the converter stops in the current system, the insulation is designed to spoil, preventing damage to the GPHS, and also ending the mission. An alkali-metal Variable Conductance Heat Pipe (VCHP) has been designed to allow multiple stops and restarts of the Stirling convertor in an Advanced Stirling Radioisotope Generator (ASRG). When the Stirling convertor is turned off, the VCHP will activate when the temperatures rises $30^{\circ} \mathrm{C}$ above the setpoint temperature. A prototype VCHP with sodium as the working fluid was fabricated and tested in both "gravity aided" and "against gravity" conditions for a nominal heater head temperature of $790^{\circ} \mathrm{C}$. The results show very good agreement with the predictions and validate the model. The gas front was located at the exit of the reservoir when heater head temperature was $790^{\circ} \mathrm{C}$ while cooling was $\mathrm{ON}$, simulating an operating Advanced Stirling Converter (ASC). When cooling stopped, the temperature increased by $30^{\circ} \mathrm{C}$, allowing the gas front to move past the radiator, which transferred the heat to the case. After resuming the cooling flow, the front returned at the initial location turning OFF the VCHP. The “against gravity” working conditions showed a colder reservoir and faster transients.
\end{abstract}

\section{Introduction}

TN a Stirling radioisotope power system, one or more General Purpose Heat Source (GPHS) modules supply heat 1 to a Stirling convertor. This heat is used to generate electric power, while the waste heat is radiated to space. The maximum allowable GPHS module operating temperature is set by the iridium cladding around the fuel. The GPHS module is designed so that it will not release radioisotopes, even under such postulated events as a launch vehicle explosion, or reentry through the earth's atmosphere. However, if the iridium cladding is overheated, grain boundary growth can weaken the cladding, possibly allowing radioisotopes to be released during an accident. Once the GPHS is installed in the radioisotope Stirling system, it must be continually cooled. Normally, the Stirling convertor removes the heat, keeping the GPHS modules cool. There are three basic times when it may be desirable to stop and restart the Stirling convertor:

1) During installation of the GPHS

2) During some missions when taking scientific measurements to minimize electromagnetic interference and vibration

3) Any other unexpected stoppage of the convertor during operation on the ground or during a mission.

In the current system, the insulation will spoil to protect the GPHS from overheating. A VCHP could potentially allow convertor operation to be restarted, depending on the reason for stoppage. It would also save replacing the insulation after such an event during ground testing.

A. VCHP Provides Back Up Cooling for the Stirling Radioisotope Power System

The schematics in Fig. 1 show the basic concept of the VCHP integrated with a Stirling engine. A GPHS module supplies heat to the heat collector which, in turn, wraps around the lower end of the Stirling engine's heater head, so

${ }^{1}$ R\&D Engineer, Aerospace Products.

${ }^{2}$ Lead Engineer, Aerospace Products, AIAA member. Bill.Anderson@1-act.com.

${ }^{3}$ R\&D Engineer, Aerospace Products. 
the normal heat flow path is GPHS - heat collector - heater head. The annular evaporator of the VCHP wraps around the heat collector so, during normal operation, vapor is approximately at the heater head's temperature. The noncondensable gas (NCG) charge in the system is sized so the radiator is blocked during normal operation (see Fig. 1(a)). When the Stirling engine is stopped, the temperature of the entire system starts to increase. Since the system is saturated, the working fluid vapor pressure increases as the temperature increases. This compresses the NCG. As shown in Fig. 1b, this opens up the radiator. Once the radiator is fully open, all of the heat is dumped to the radiator, and the temperature stabilizes. Once the Stirling engine starts operating again, the vapor temperature and pressure start to drop. The non-condensable gas blankets the radiator, and the system is back to the normal state (Fig. 1(a)).

\section{STIRLING ENGINE ON}

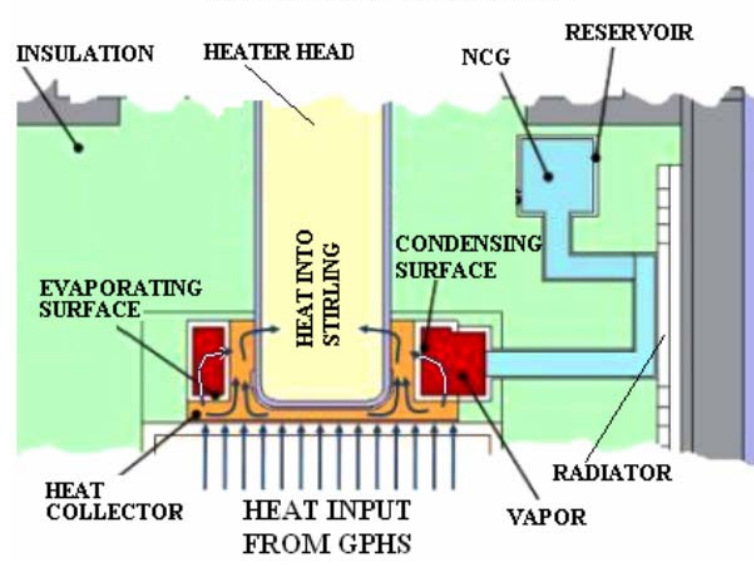

a)

\section{STIRLING ENGINE OFF}

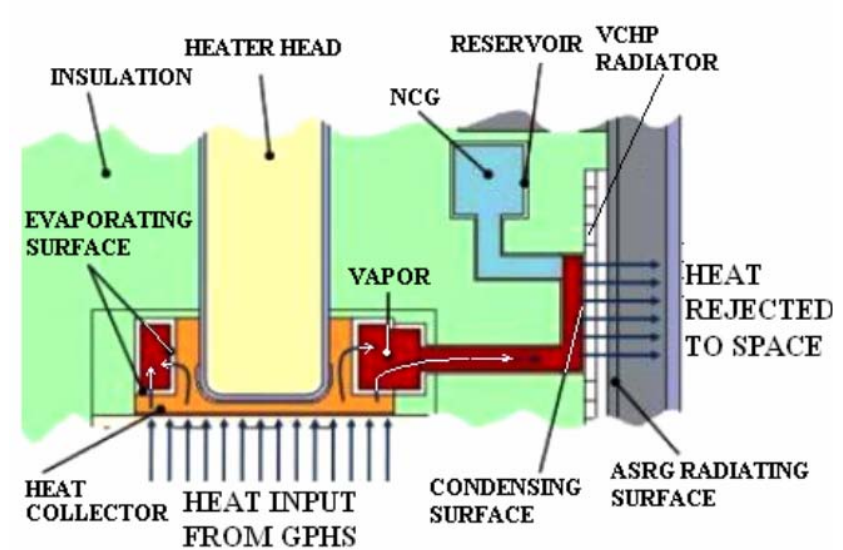

b)

Figure 1. a) VCHP delivers heat to the heater head when the Stirling engine is working. b) VCHP dumps heat to the radiator when the Stirling engine is not working.

\section{B. Base Line Design}

The Advanced Stirling Radioisotope Generator (ASRG) ${ }^{1}$, with an $850^{\circ} \mathrm{C}$ heater head temperature, was selected as the baseline design. The system consists of two Advanced Stirling Convertors (ASCs), mounted back to back for dynamic balance. Heat to each ASC is supplied by one GPHS module. During operation, a heat collector is used to conduct the heat from the GPHS into the Stirling heater head, see Fig. 2(a). A cold-side adapter flange (CSAF), shown in Fig. 2(b) is used to conduct the waste heat from the Stirling convertor cold side to the ASRG housing, where it radiates to space. The CSAF is fabricated from copper, and serves as a structural member. The cold-end flange temperature is primarily set by the sink temperature seen by the ASRG radiating housing, which varies from earth (including launch) environments to deep space. Its operating temperature ranges from 40 to $120^{\circ} \mathrm{C}$.

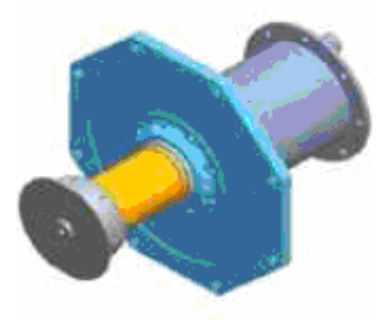

a)
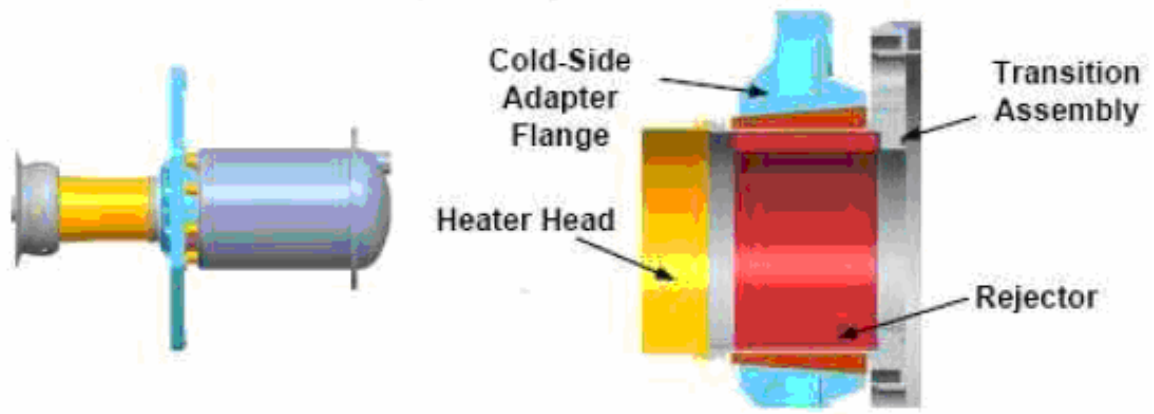

b)

Figure 1. (a) Stirling Converter with heat collector and Cold-Side Adapter Flange. (b) Cold-Side Adapter Flange. Taken from Chan, Wood, and Schreiber (2007).

\section{First Prototype VCHP Design}

Figure 3 is a schematic of the VCHP integrated with the Advanced Stirling Convertor (ASC) to provide back-up cooling. Since an ASRG consists of a pair of Stirling converters mounted head to head, this schematic corresponds 
to the lower portion of half of the ASRG system. The VCHP evaporator is wrapped around the heat collector so the original ASC configuration is not modified. The condenser is attached to the internal radiator while the reservoir is embedded inside the insulation, under the CSAF. The VCHP is designed in such a way that, during normal operation of the Stirling convertor, the working fluid vapor - NCG interface front is located at the exit of the evaporator, as far as possible from the condenser to minimize the heat losses. When the Stirling converter is stopped, the NCG front is located at the top of the condenser and the heat is radiated to the ASRG wall and thence into the environment.

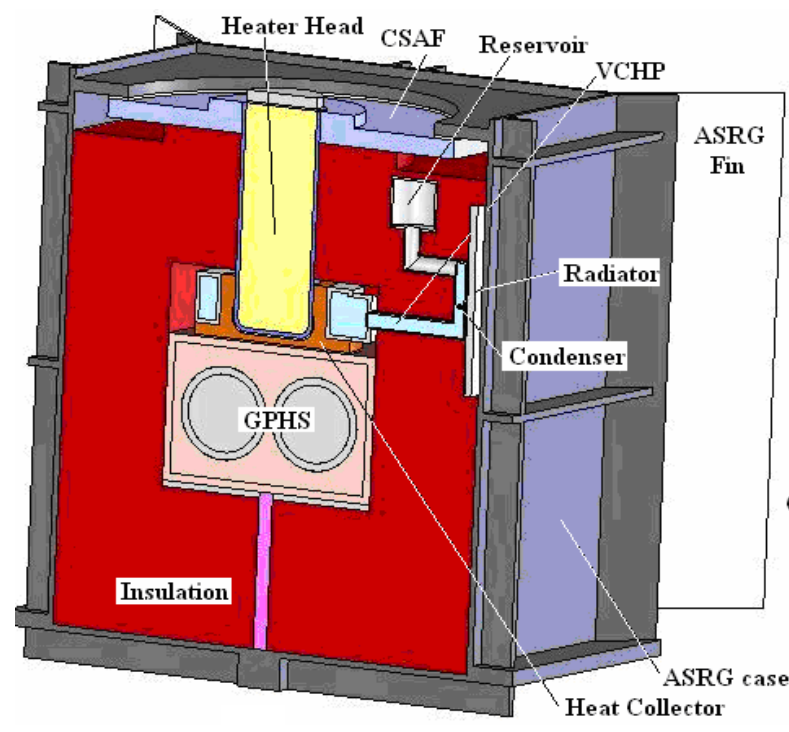

a)

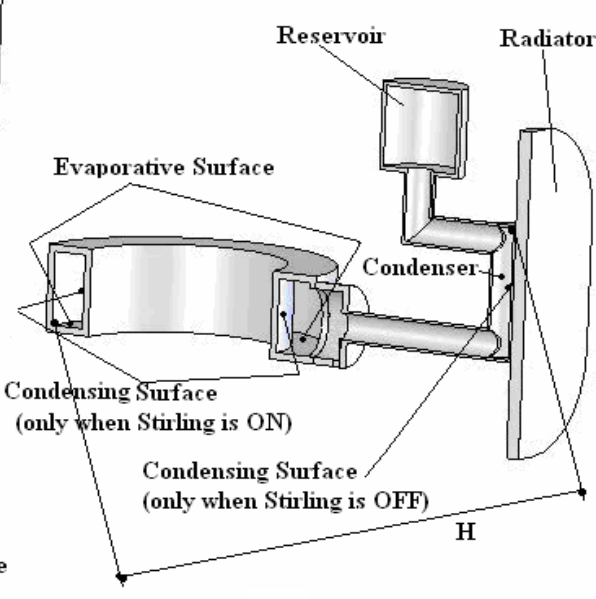

b)

Figure 3. (a) VCHP-ASRG system (b) First prototype VCHP with internal condenser and the reservoir embedded within the insulation.

The VCHP dimensions are driven by both configuration and the wick design. Relevant parameters regarding the design and the fabricated VCHP are presented below in Table 1.

Table 1. VCHP physical and geometrical parameters.

\begin{tabular}{|c|c|c|}
\hline & Parameter & Value \\
\hline \multirow{3}{*}{ General } & Material & SS304 \\
\hline & Number of moles of NCG (Ar) [moles] & 0.00025 \\
\hline & Mass [g] & 302 \\
\hline \multirow{3}{*}{ Evaporator } & I.D. minimum (it matches the heat collector OD) [in] & 1.87 \\
\hline & O.D. maximum (external diameter) [in] & 2.75 \\
\hline & Height (inside) [in] & 0.741 \\
\hline \multirow{2}{*}{$\begin{array}{c}\text { Section between Evaporator and } \\
\text { Condenser }\end{array}$} & Total length [in] & 1.82 \\
\hline & I.D. [in] & 0.256 \\
\hline \multirow{2}{*}{ Condenser } & I.D. [in] & 0.35 \\
\hline & Length [in] & 1.2 \\
\hline \multirow{5}{*}{ Radiator } & Material & Nickel \\
\hline & Area $\left[\mathrm{in}^{2}\right]$ & 11 \\
\hline & Thickness [in] & 0.3 \\
\hline & Emissivity & 0.85 \\
\hline & Fin Efficiency & 0.54 \\
\hline \multirow[t]{2}{*}{ Section between Condenser and Reservoir } & Total length [inch] & 3.65 \\
\hline & ID [inch] & 0.256 \\
\hline Reservoir & Volume [inch ${ }^{3}$ ] & 1.285 \\
\hline
\end{tabular}


Table 2. Capillary pumping capability and pressure drops (Pa) for the design at $T_{\max }=\mathbf{8 8 0}^{\circ} \mathrm{C}$.

\begin{tabular}{|c|c|c|c|c|c|}
\hline Design Stage & Capillary Pressure & $\begin{array}{c}\text { Total Pressure } \\
\text { Drop }\end{array}$ & Gravity Head & $\begin{array}{c}\text { Liquid Pressure } \\
\text { Drop }\end{array}$ & $\begin{array}{c}\text { Vapor Pressure } \\
\text { Drop }\end{array}$ \\
\hline New Design & 1872 & 1119 & 848 & 222 & 48.9 \\
\hline
\end{tabular}

Pressure drops along the VCHP are presented in Table 2, for sodium working fluid at the maximum vapor temperature of $880^{\circ} \mathrm{C}(1153 \mathrm{~K})$, when the VCHP is active. The total pressure drop (the sum of the three main components, due to gravity and the liquid and vapor flows) is smaller than the capillary pressure. The resultant pumping capability of $1872 \mathrm{~Pa}$ overcomes the total pressure drop of $1119 \mathrm{~Pa}$. The most dominant pressure drop component, due to gravity, was calculated for the maximum possible elevation, $\mathrm{H}$, measured on the diagonal, which was 4.6 inches. The VCHP is designed to operate in any orientation.

Performance limitations for the first prototype design are shown in Fig. 4. The nominal power $(250 \mathrm{~W})$ that the VCHP has to carry is represented with dashed line. As expected, at lower temperatures, viscous

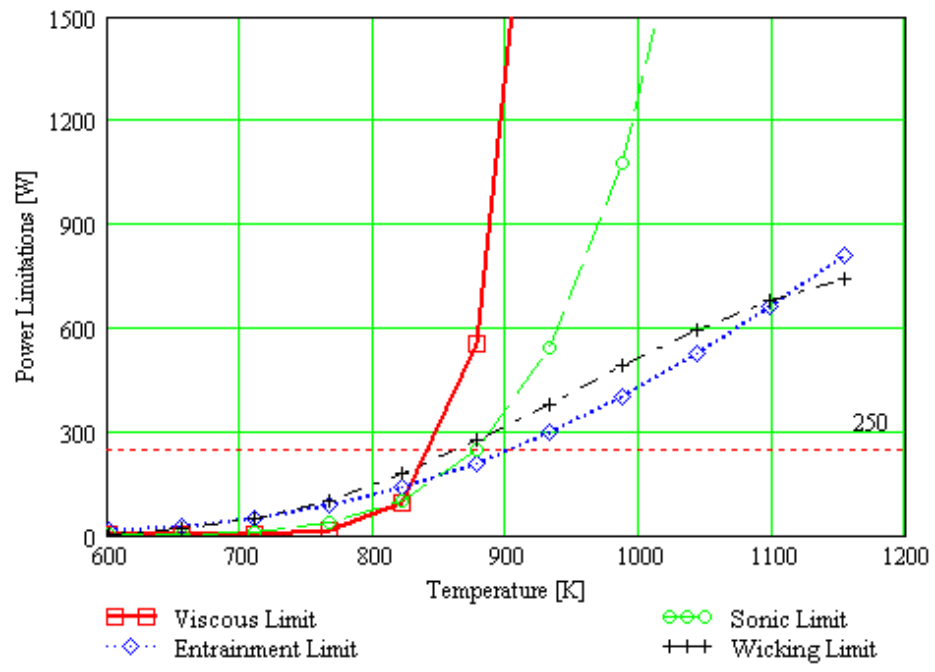

Figure 4. Performance limitations for the first VCHP prototype.

and sonic limitations drastically restrict the pipe performance. Note that, unlike the capillary limit, these are not actually limits to the heat pipe performance. If either limit is reached with a constant heat flux source, the heat pipe temperature will increase until the limit no longer applies. At the nominal working temperature of $880^{\circ} \mathrm{C}(1153 \mathrm{~K})$, the wicking limit is the most restrictive but is at much higher values than the GPHS power.

\section{Experiment}

The first prototype VCHP test setup is shown in Fig. 5. The "D" shaped condenser is attached to the nickel radiator through the flat surface. The nickel radiator is used for convenience in testing the prototype, the final VCHP will have a carbon-carbon radiator. Heat radiates from the radiator to an ASRG wall simulator, which, in turn, radiates into the ambient or to a cold wall inside the vacuum chamber. The VCHP was designed to operate with a baseline temperature of $790^{\circ} \mathrm{C}$, turning on when the vapor temperature reached $820^{\circ} \mathrm{C}$.

Figure 5(a) shows the locations of the thermocouples used to measure the temperature distribution along the actual VCHP. Most of the thermocouples were welded to the pipe except thermocouples 24, 28 and 33. These thermocouples were installed into thermo-wells to measure vapor temperatures in the evaporator (TC 24 and 28) and NCG temperature in reservoir (TC 33). Condenser temperatures are measured by thermocouples 4, 5, and 9 while radiator temperatures are measured by thermocouples $6,7,8,10,11$, and 12 . The remaining thermocouples shown in Fig. 5(a) measure temperature distributions along the sections between the evaporator and condenser (thermocouples 1 , 2, and 3) and between the condenser and the reservoir (thermocouples 13 through 21). The average distance between the thermocouple locations was approximately 0.4 inches except between thermocouples 24/28 and 1 where the distance was approximately 1.5 inches and between thermocouple 21 and 33 (reservoir) where the distance was approximately 0.9 inches.

Figure 5(b) shows the VCHP integrated in the experimental setup. The GPHS is simulated by a $\mathrm{MoSi}_{2}$ heater, which radiantly heats the bottom of the heat collector. Heat removal by the Stirling convertor is simulated by a steady flow of air that travels down the central tube, and travels up the outer tube, exiting at the top of the other tube.

Thermocouples 22 and 26 monitor the coolant (compressed air) IN and OUT temperatures. Temperatures in the evaporating/condensing areas of the "donut" are measured in the heat collector walls by thermocouples 25, just under the evaporation interface, and 23, next to the condensation interface.

To protect the heater, the bulk of measurements carried during the testing of the first prototype were run at a vapor temperature lower than the nominal one $\left(850^{\circ} \mathrm{C}\right)$. The vapor temperature of $790^{\circ} \mathrm{C}$ was chosen for most of the 
tests. In this case, for 0.00025 moles of NCG, the cold and hot reservoir temperatures resulted as $208^{\circ} \mathrm{C}$ and $382^{\circ} \mathrm{C}$ respectively for the VCHP activation temperature difference of $30^{\circ} \mathrm{C}$.

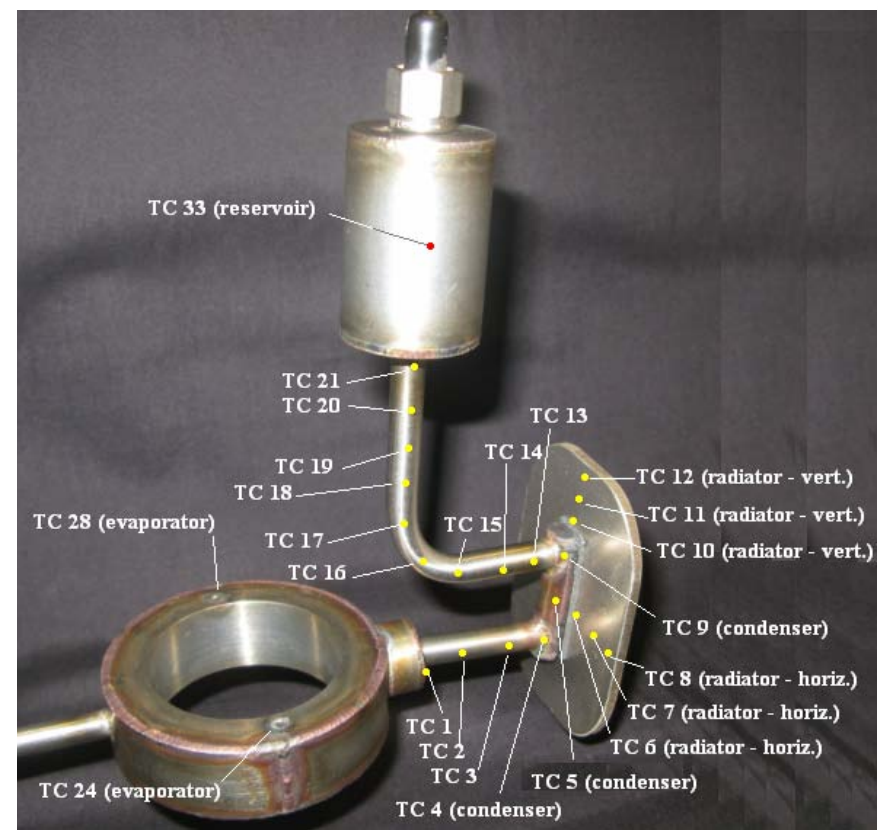

a)

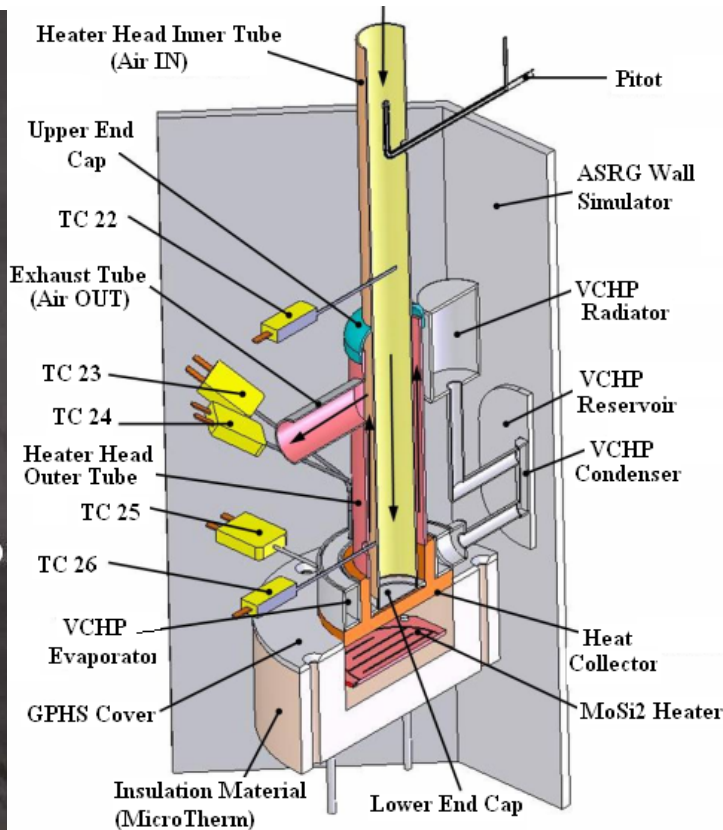

b)

Figure 5. VCHP integration with the experimental setup a) Fabricated first prototype VCHP, b) Test setup.

\section{A. Preliminary Experimental Procedure and Results}

A preliminary experiment with the pipe "gravity aided" was carried out to find the coolant (air) flow rate, heat losses and the electrical power to be delivered by the variac. Gravity aided is the orientation shown in Figure 5, where sodium can drip back from the radiator to the annular evaporator. This preliminary experiment was carried in three sequences:

During Sequence 1, power was increased, activating the VCHP, until the front settled at the end of the condenser (TC 9) reaching steady state conditions with no cooling (see Figure 6). The vapor temperature reached $820^{\circ} \mathrm{C}$, resulting in a $30^{\circ} \mathrm{C}$ temperature rise above the design vapor temperature of $790^{\circ} \mathrm{C}$ while the reservoir temperature was approximately $373^{\circ} \mathrm{C}$ (compared to $382^{\circ} \mathrm{C}$ required by the model for hot reservoir-VCHP ON). Total power delivered by the variac to maintain steady state was $455 \mathrm{~W}$. The heater temperature was $1033^{\circ} \mathrm{C}$ resulting in a

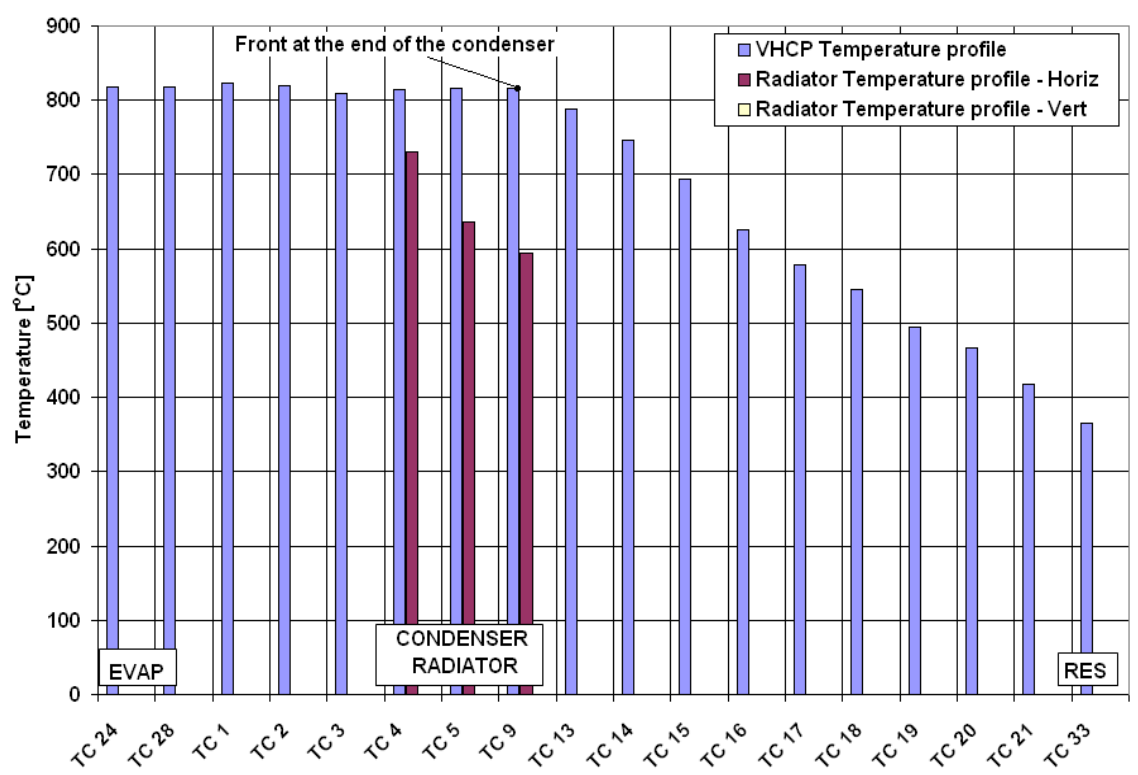

Figure 6. Preliminary experiment: Sequence 1- front reaches the end of the condenser with no cooling, at a vapor temperature of $820^{\circ} \mathrm{C}$, reservoir temperature of $373^{\circ} \mathrm{C}$ and a total power of $455 \mathrm{~W}$. $213^{\circ} \mathrm{C}$ temperature difference between the heater and the sodium vapor. The average radiator and radiated wall temperatures were $637^{\circ} \mathrm{C}$ and $95.5^{\circ} \mathrm{C}$, respectively. 
During Sequence 2, the total electrical power was kept constant (at 455W) while the cooling air was started (simulating Stirling as ON) and increased in step wise increments. The front retracted and settled at the exit of the evaporator (see Fig. 7) when the vapor temperature was $790^{\circ} \mathrm{C}$ and the reservoir temperature was $248^{\circ} \mathrm{C}$ (compared to the $210^{\circ} \mathrm{C}$ required by the model for the cold reservoir situation - VCHP OFF). The heater temperature was $1003^{\circ} \mathrm{C}$ maintaining the same temperature difference, $213^{\circ} \mathrm{C}$, between the heater and the sodium vapor. The average radiator and radiated wall temperatures were $275^{\circ} \mathrm{C}$ and $44^{\circ} \mathrm{C}$, respectively. The air-cooling used to maintain steady state within these parameters was $7.6 \mathrm{~m} / \mathrm{s}$. Although thermocouples for air IN and OUT temperatures were provided for calorimetric calculations, the power carried by the coolant was not calculated because of the poor accuracy of the volumetric air flow rate calculated from the air velocity measured by the pitot tubee. Therefore, only air velocity was considered. It represented a reference when comparing cooling conditions from one situation to another. The value of $7.6 \mathrm{~m} / \mathrm{s}$ was used throughout the experiment.

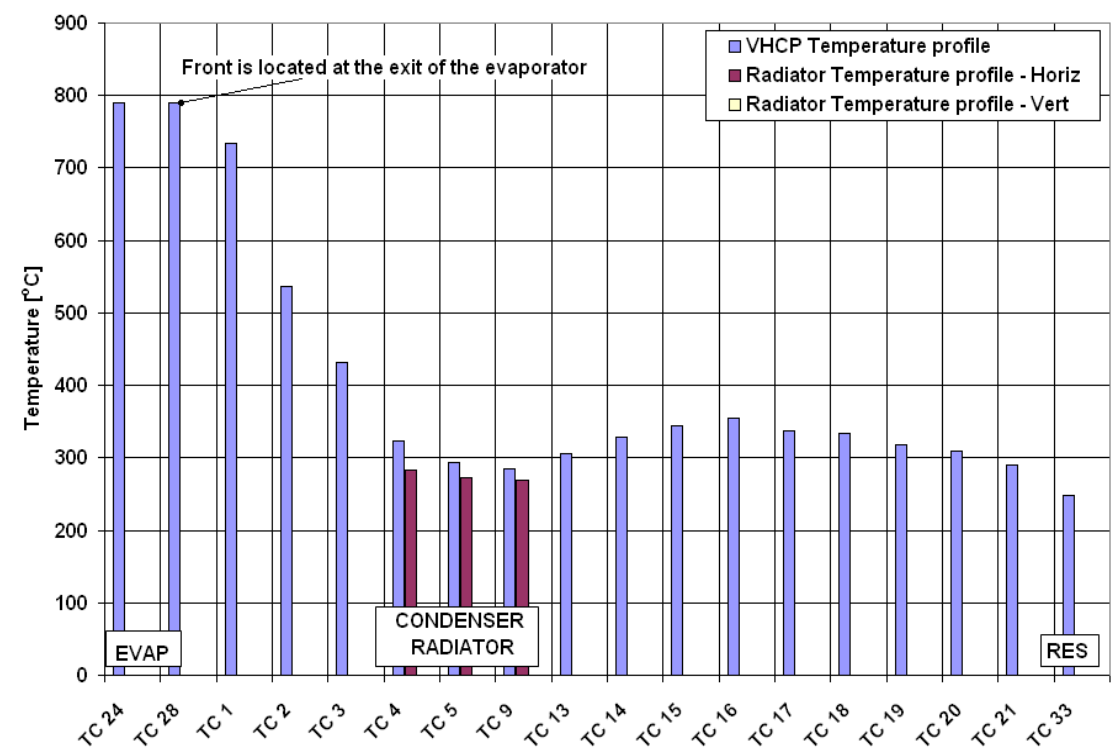

Figure 7. Preliminary experiment: Sequence 2 - front settles at the exit of the evaporator at a vapor temperature of $790^{\circ} \mathrm{C}$, reservoir temperature of $248^{\circ} \mathrm{C}$, total applied power of $455 \mathrm{~W}$ and air cooling at $7.6 \mathrm{~m} / \mathrm{s}$.

During Sequence 3, heat losses

through insulation were evaluated by simultaneously decreasing the total power and air velocity while maintaining constant vapor temperature at $790^{\circ} \mathrm{C}$. When air flow stopped, steady state at $790^{\circ} \mathrm{C}$ vapor temperature was achieved with a power of $162 \mathrm{~W}$.

In conclusion, the preliminary experiment provided information regarding both the accuracy of the model and the necessary parameters for further experimentation. The conclusions are summarized below:

1) The gas front was located at the end of the condenser for the prescribed vapor temperature of $820^{\circ} \mathrm{C}$. It represents a $30^{\circ} \mathrm{C}$ temperature increase from the normal operation vapor temperature of $790^{\circ} \mathrm{C}$ taking into account a NCG charge of 0.00025 moles.

2) Total power delivered to maintain steady state was $455 \mathrm{~W}$. It includes both power carried by the VCHP (and rejected by the radiator) and heat losses through the insulation.

3) The hot reservoir temperature was approximately $373^{\circ} \mathrm{C}$. The difference between the design cold reservoir temperature of $382^{\circ} \mathrm{C}$ and the measured temperature did not have noticeable effects on front location.

4) The gas front was located between the thermocouples $24 / 28$ and 1 at constant power and vapor temperature $\left(790^{\circ} \mathrm{C}\right)$ with cooling applied, in other words, roughly at the evaporator exit. The difference of $38^{\circ} \mathrm{C}$ between the design cold reservoir temperature $\left(210^{\circ} \mathrm{C}\right)$ and the actual temperature $\left(248^{\circ} \mathrm{C}\right)$ might have an effect on front location by slightly pushing it inside the evaporator. However, this was not observable because of the large distance between thermocouples 24/28 and 1 of approximately 1.5 inch.

5) A coolant velocity of $7.6 \mathrm{~m} / \mathrm{s}$ will be used as reference during subsequent tests.

6) Steady state conditions at $790^{\circ} \mathrm{C}$ with no cooling showed heat losses of $162 \mathrm{~W}$.

7) The difference between the total power ( $455 \mathrm{~W}$ ) and heat losses (162 W - that might slightly change during cooling condition) results in an approximately $293 \mathrm{~W}$ of power carried by the VCHP. However, this power was considered as the upper limit of the uncertainty range because the heat losses of $162 \mathrm{~W}$ were measured at $790^{\circ} \mathrm{C}$ while the total power of $455 \mathrm{~W}$ was measured at $820^{\circ} \mathrm{C}$. Therefore, because of the heat losses that might be higher than $162 \mathrm{~W}$ during the VCHP ON situation, the power carried by the VCHP might be lower than $293 \mathrm{~W}$.

8) The power carried by the VCHP is higher than anticipated because of the radiator, which is oversized. 


\section{B. Experimental Procedure - "Gravity Aided" and "Against Gravity”}

The "gravity aided" tests were carried out with the VCHP in the orientation shown in Figure 5, where condensate can drain down from the condenser to the evaporator. In the "against gravity" tests, the VCHP was turned upside down. Both the "gravity aided" and "against gravity" tests were carried out in four sequences each:

1) Sequence 1 evaluated the heat losses through the insulation. The power necessary to reach steady state conditions at $790^{\circ} \mathrm{C}$ vapor temperature, with no cooling, was considered as heat losses through insulation to the ambient.

2) Sequence 2 simulated the ASC ON and VCHP OFF situation. Cooling air was ON $(7.6 \mathrm{~m} / \mathrm{s})$ and power increased to approximately $450 \mathrm{~W}$ until a new steady state was obtained at the same vapor temperature $790^{\circ} \mathrm{C}$.

3) Sequence 3 simulated the ASC OFF and VCHP ON situation. Cooling air was turned OFF letting the front move toward the end of the condenser to turn the VCHP ON and reach steady state in the new conditions (vapor temperature around $820^{\circ} \mathrm{C}$ ).

4) Sequence 4 simulated the new ASC ON and VCHP OFF situation after the front retracted. Cooling air was turned ON again $(7.6 \mathrm{~m} / \mathrm{s})$ letting the front retract toward the evaporator to turn the VCHP OFF and reestablish the steady state conditions from Sequence 2 (vapor temperature of $790^{\circ} \mathrm{C}$ ).

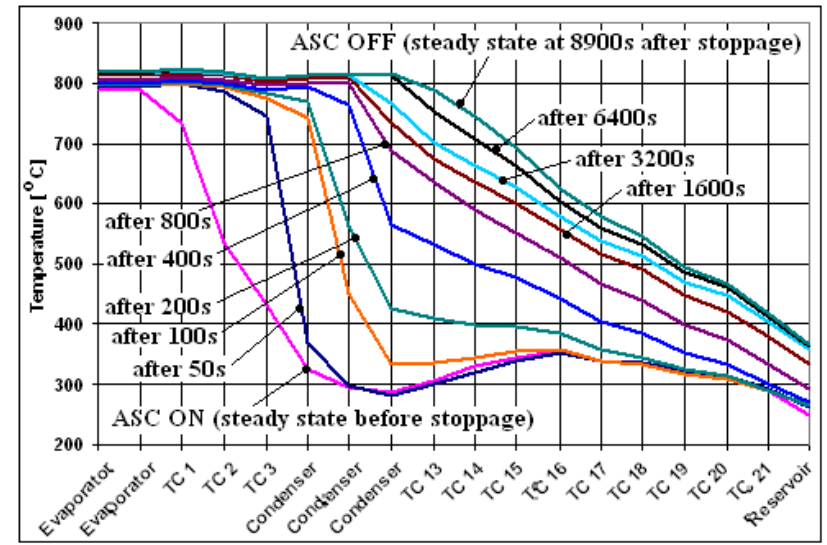

a)

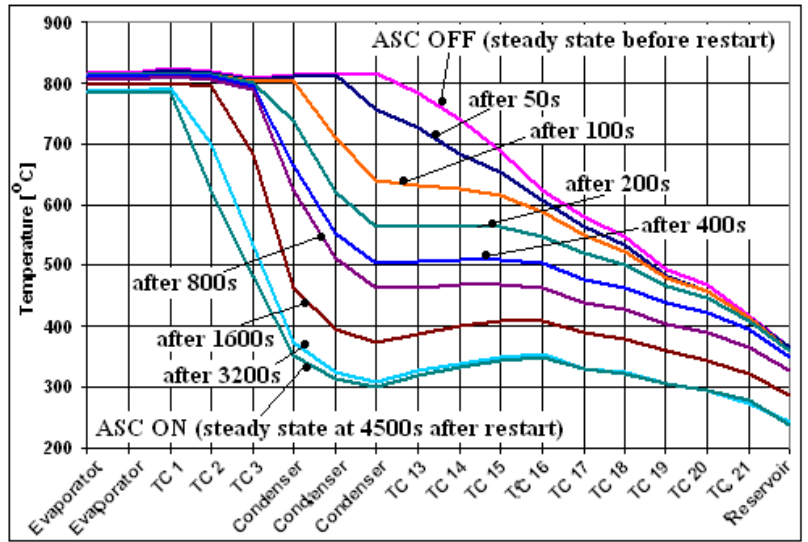

b)

Figure 8. VCHP temperature distributions during a) Sequence 3 (front moves toward the end of the condenser to turn the VCHP ON) and b) Sequence 4 (front retracts toward the evaporator to turn the VCHP OFF) of the "gravity aided" experiment

\section{C. “Gravity Aided” Experiment}

As mentioned before, the "gravity aided" experiment was carried out very close to the most favorable conditions from VCHP performance point of view, with the evaporator at the bottom and the reservoir on top. Transient VCHP temperature profiles are presented below in Fig. 8. In Sequence 3 (Figure 8a), the sequence starts with the lowest temperature profile, where the cooling air is on (ASC ON). The evaporator is at $790^{\circ} \mathrm{C}$, and all of the heat is going from the heater, through the annular evaporator, and into the cooling air. The radiator is off, with temperatures below $300^{\circ} \mathrm{C}$. Once cooling is turned off, (ASC OFF), the system starts to heat up, and the NCG gas front moves toward the

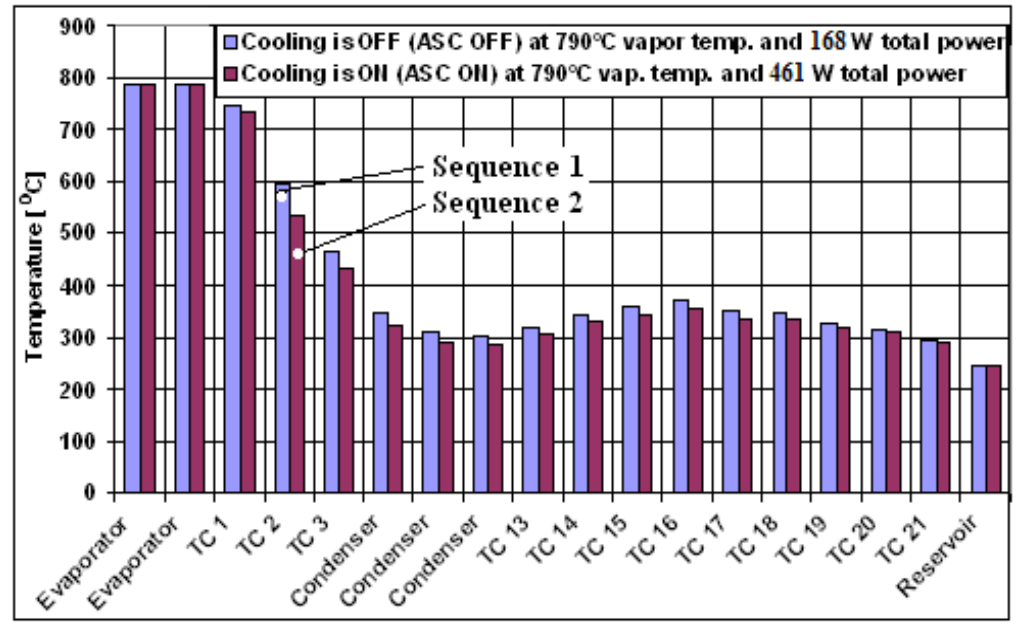

Figure 9. VCHP temperature distributions at the end of the first two sequences of the "gravity aided" experiment. condenser. As it travels up the condenser, 


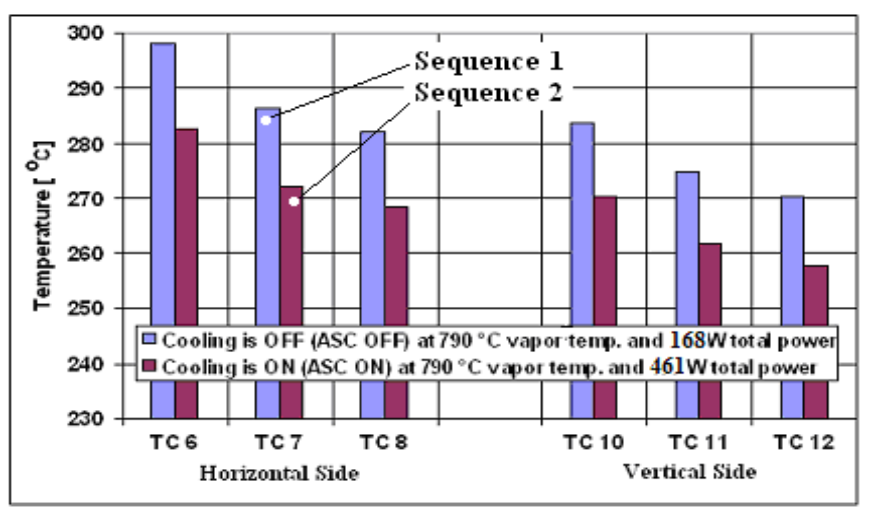

Figure 10. Radiator temperature distributions at the ends of the first two sequences of the "gravity aided" experiment.

heat is transferred to the simulated ASRG wall, where it is transferred to ambient by radiation and natural convection. The

Sequence 4, shown in Figure 8b, was run immediately after Sequence 3, so the top curves in Figures $8 \mathrm{a}$ and $\mathrm{b}$ are identical. When cooling is turned on (ASC ON), the system gradually cools. The temperature and pressure in the vapor drop, and the NCG front moves back towards the annular evaporator. As expected, the gas front moves at a faster rate in the beginning and slower toward the end of each of the two sequences, as steady state conditions (ends of the sequences) are approached. It can be observed that the front is slower during Sequence 3 (VCHP turning ON) than during Sequence 4 (VCHP turning OFF). The reason is

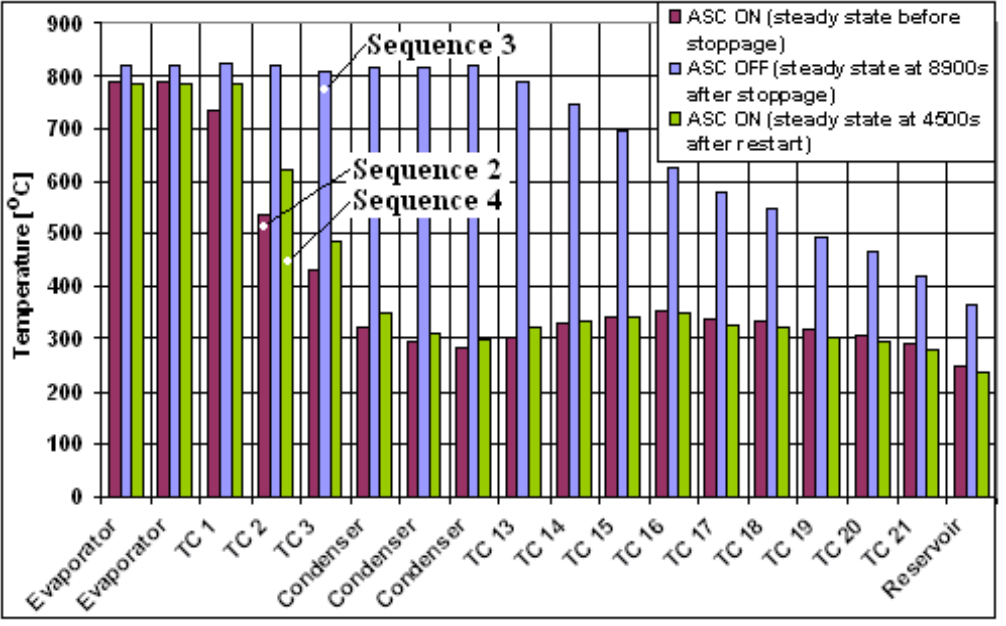

Figure 11. VCHP temperature distributions at the ends of the last three sequences of the "gravity aided" experiment.

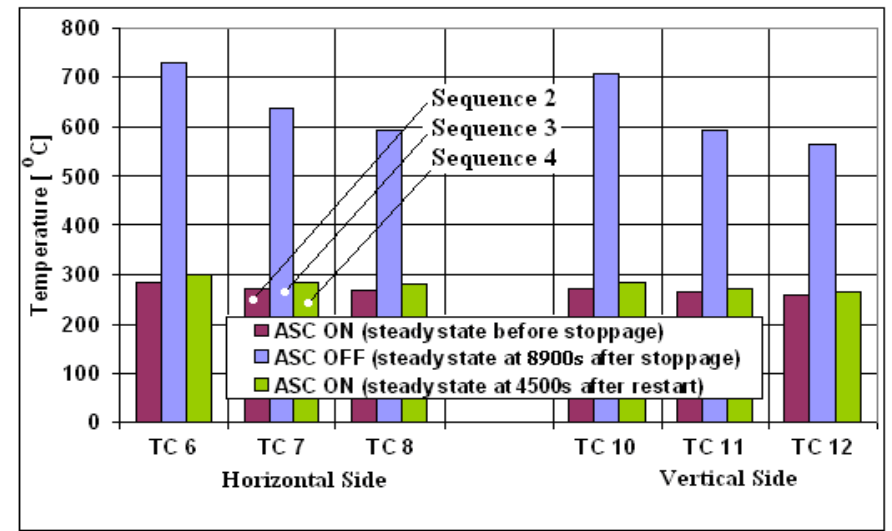

Figure 12. Radiator temperature distributions at the ends of the last three sequences of the "gravity aided" experiment unclear yet. However, the general transient duration will be compared with the results from the "against gravity" case.

Figure 9 shows the temperature distributions along the VCHP at the ends of the first two sequences of the "gravity aided" experiment. It can be observed from Sequence 2 that, when cooling is $\mathrm{ON}$, all the temperatures are slightly lower except for the evaporator and reservoir. This is because the heater head is cooler due to the air flow, and slightly cools the condenser and reservoir. However, the front is located at the exit of the evaporator at a vapor temperature of $790^{\circ} \mathrm{C}$, reservoir temperature of $249^{\circ} \mathrm{C}$, heat losses of $168 \mathrm{~W}$, total power of 461 $\mathrm{W}$ and air cooling velocity of $7.6 \mathrm{~m} / \mathrm{s}$. The reservoir temperature of $249^{\circ} \mathrm{C}$ is very close to the temperature without cooling at the same vapor temperature.

Figure 10 presents the radiator temperature distributions at the ends of the first two sequences of the "gravity aided" experiment. Although the vapor temperatures are the same during these two sequences, the cooled situation determines lower temperatures on the radiator due to the proximity of the heater head, which now is cooler. This difference shows lower losses for the cooled situation.

The temperature distributions at the ends of the last three sequences are represented simultaneously in Fig. 11. During sequence 2, the front was located, under steady state conditions, at the exit of the evaporator for a $790^{\circ} \mathrm{C}$ vapor temperature, 7.6 $\mathrm{m} / \mathrm{s}$ cooling air flow velocity, $461 \mathrm{~W}$ total power, and $249^{\circ} \mathrm{C}$ cold reservoir temperature. Sequence 3 started when the air was turned OFF. Consequently, the front moved toward the condenser to turn the VCHP ON. It settled under steady conditions at the end of the condenser when vapor temperature reached an average value of $821^{\circ} \mathrm{C}$ and hot reservoir temperature reached $374^{\circ} \mathrm{C}$. This was the end of Sequence 3. When air cooling was turned ON again (start 
of Sequence 4), at the same velocity, the front returned to the evaporator. At the end of Sequence 4, the front settled at the exit of the evaporator extension (TC 1) for a $790^{\circ} \mathrm{C}$ vapor temperature and $241^{\circ} \mathrm{C}$ cold reservoir temperature. The two temperature distributions corresponding to the second and fourth sequences present noticeable differences. The reservoir temperature is slightly lower for the fourth sequence allowing the front to settle at TC 1 . This rather advanced position of the front determines higher temperatures on the VCHP section between the evaporator and condenser (thermocouples 1 through 4). This difference between the two temperature profiles shows that steady state has not yet been reached.

Radiator temperature profiles are presented in Fig. 12. An approximate temperature drop of $90^{\circ} \mathrm{C}$ can be observed for the ASC OFF case (VCHP ON) between the vapor $\left(820^{\circ} \mathrm{C}\right)$ and thermocouple 6 on the radiator.

\section{D. “Against Gravity” Experiment}

In the "against gravity", case the VCHP was tested upside down (in vertical position) with the evaporator above the reservoir (opposite to the "gravity aided" case). The results were in general in agreement with the model and no VCHP performance drawbacks were observed. Most of the findings and conclusions regarding the VCHP behavior are similar to the previous, "gravity aided" case. However, significant reservoir temperature and transient time differences were observed and we believe that they are related.

Temperature distributions at the ends of the last three (2, 3, and 4) experimental sequences of the "against gravity" case are presented in Figure 13. The general

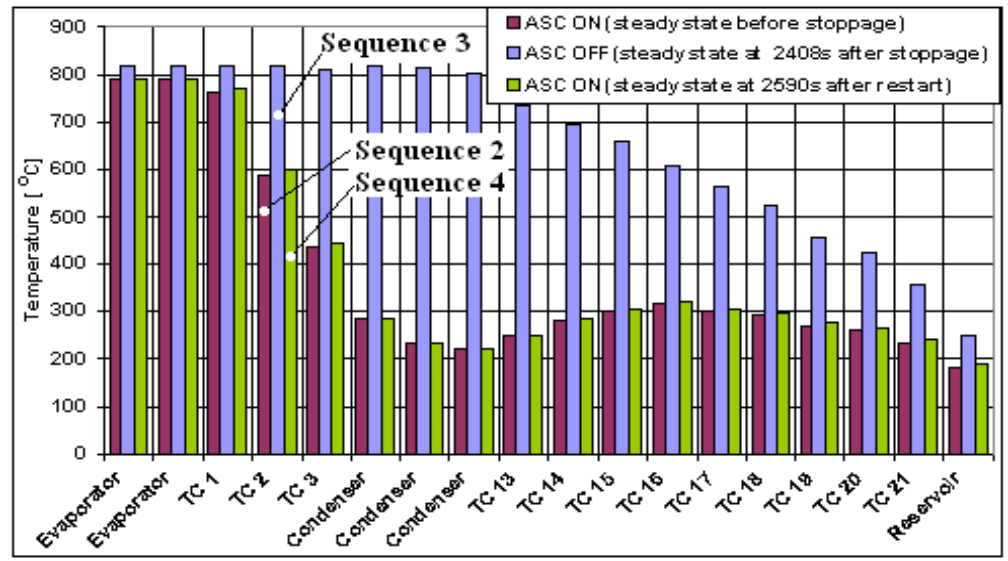
progression of the sequences would be similar to the previous, gravity assisted case. Again, although Sequence 4 was considered completed when no noticeable vapor temperature variation around $790^{\circ} \mathrm{C}$ was detected, a true steady state situation was not reached. The gas front is slightly advanced toward the condenser despite all the VCHP temperatures which are higher (including the reservoir) than those in Sequence 2. Table 4 shows a summary of the reservoir temperatures at the ends of Sequences 2, 3, and 4 in both "gravity aided" and "against gravity" cases. It can observed that all reservoir temperatures during the "against gravity” experiment are significantly lower than the corresponding cases of the "gravity aided" experiment.

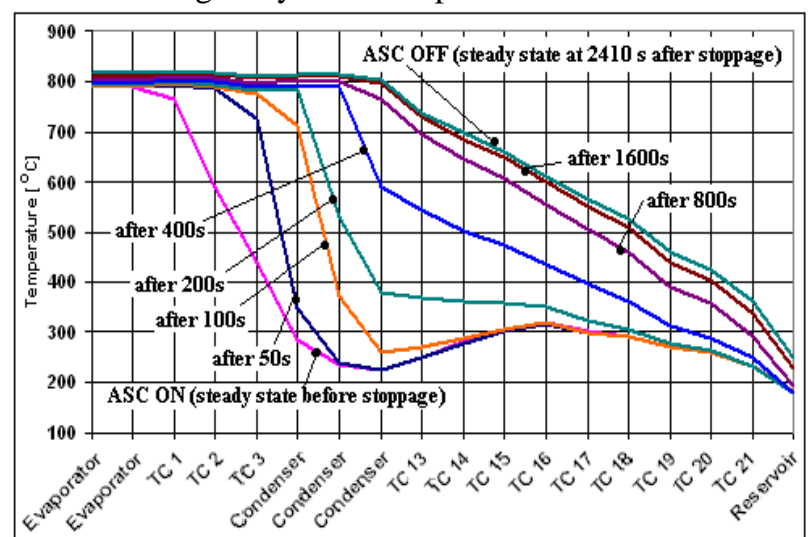

a)

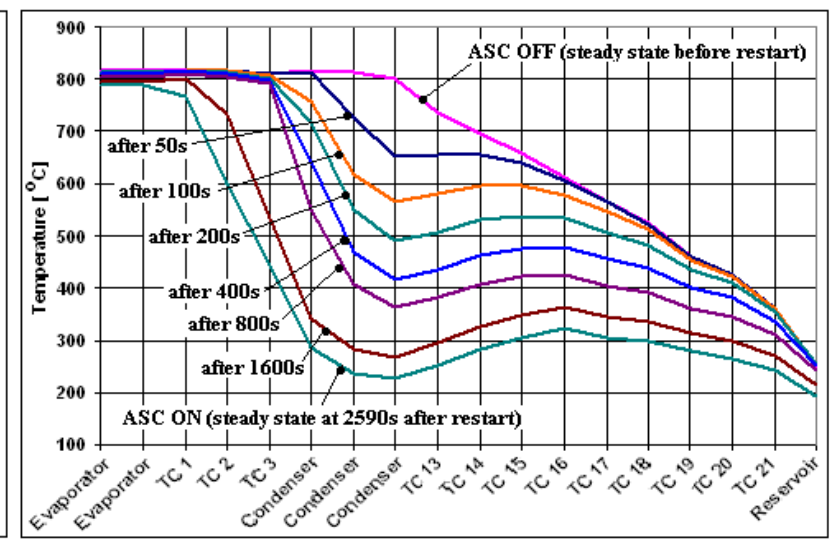

b)

\begin{tabular}{|c|c|c|c|}
\hline Case & $\begin{array}{c}\text { Reservoir } \\
\text { Status }\end{array}$ & Sequence & $\begin{array}{c}\text { Temperature } \\
{\left[{ }^{\circ} \mathbf{C}\right]}\end{array}$ \\
\hline \multirow{2}{*}{$\begin{array}{c}\text { Gravity } \\
\text { Aided }\end{array}$} & Cold & 2 & 247 \\
\cline { 2 - 4 } & Hot & 3 & 366 \\
\cline { 2 - 4 } & Cold & 4 & 243 \\
\hline \multirow{2}{*}{$\begin{array}{c}\text { Against } \\
\text { Gravity }\end{array}$} & Cold & 2 & 180 \\
\cline { 2 - 4 } & Hot & 3 & 250 \\
\cline { 2 - 4 } & Cold & 4 & 213 \\
\hline
\end{tabular}

Figure 14. VCHP temperature distributions during a) Sequence 3 (front moves toward the end of the condenser to turn the VCHP ON) and b) Sequence 4 (front retracts toward the evaporator to turn the VCHP OFF) of the “against gravity" experiment

American Institute of Aeronautics and Astronautics 
Figure 14 shows the details of the transient state of the gas front (VCHP temperature distributions) during sequences 3 and 4 . Similar to the gravity-aided case, the gas front moved at a faster rate in the beginning of each sequence slowing down significantly, as steady state is approached. In the "against gravity" case, the front moves approximately 2 times faster in Sequence 4 and four times faster than in Sequence 3 of the "gravity aided" case. Again, it can be observed that the reservoir is significantly hotter in the "gravity aided" case than in the "against gravity" case during all sequences. Preliminarily we believe that the difference between the front velocities in the two cases, "gravity aided" and "against gravity", is due to the difference in reservoir temperatures and their transients. Faster heating of reservoir may suppress the front movement longer, causing a slower front velocity. In turn, the difference in reservoir temperatures between the two cases may be

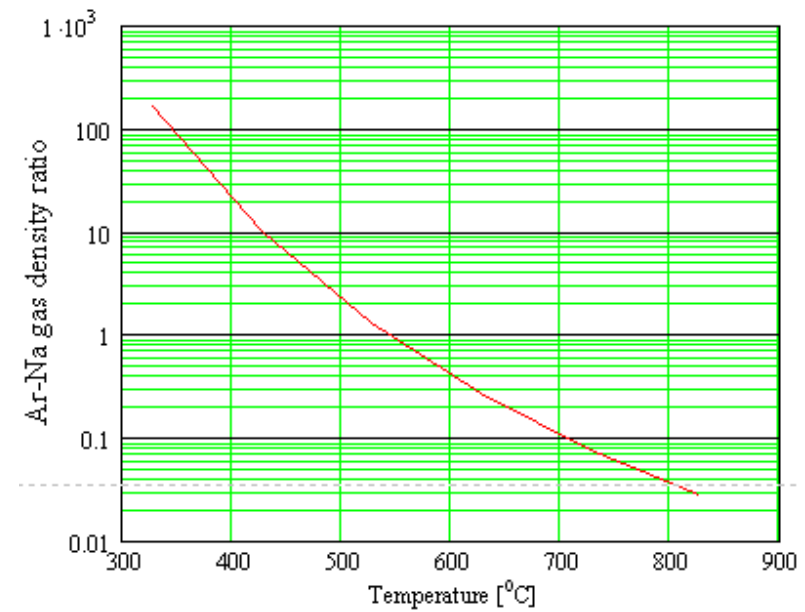

Figure 15. Argon-Sodium gas density ratio as a function of temperature.

caused by gravity effects materialized by the following two components:

1) External free convection through the insulation in the "gravity aided" case that causes a faster heating up of the reservoir.

2) Internal buoyancy forces (also in the "gravity aided" case) because of the lighter sodium vapor at the reservoir temperatures (see Fig. 15) that might also cause a more rapid heating of the reservoir. Sodium vapor that penetrates the front by diffusion (at the temperatures of the front region, sodium is heavier than argon) reach the colder zones (where it becomes lighter than the argon) and continue the upward motion, buoyancy driven, eventually reaching the reservoir and condensing. This phenomenon may not happen in the "against gravity" case allowing a lower temperature of the reservoir.

To verify this hypothesis, new measurements will be carried out for several VCHP orientations, including the horizontal one.

\section{Conclusion}

The first prototype of a VCHP has been successfully fabricated and tested. The system had a baseline temperature of $790^{\circ} \mathrm{C}$, and used sodium as the working fluid. The experimental results matched the modeling predictions very well for both gravity assisted and against gravity (upside down) working conditions. The front was located at the exit of the evaporator for $790^{\circ} \mathrm{C}$ for ASC ON (cooling was active) and VCHP OFF during steady conditions. When cooling stopped, (simulating ASC OFF), the gas front moved and settled at the end of the condenser for $820^{\circ} \mathrm{C}$ vapor temperature turning the VCHP ON. This showed a $30^{\circ} \mathrm{C}$ vapor temperature increase, as designed. Heat rejected by the radiator was about $270 \mathrm{~W}$ in both cases ("gravity assisted" and "against gravity"). When cooling was started again (simulating ASC ON), the gas front retreated to the evaporator exit to turn the VCHP OFF and settled at the same initial vapor temperature, $790^{\circ} \mathrm{C}$. VCHP performance was similar for the "against gravity" case.

The only noticeable difference between the results of the two extreme cases ("gravity assisted" and "against gravity"), were the reservoir temperature and the front traveling time. The reservoir was significantly hotter in the "gravity aided" case than in the "against gravity" case during both cold (VCHP OFF) and hot (VCHP ON) regimes. Also, the front traveling speed was approximately two times higher in the "against gravity" case than in the "gravity aided" case. A preliminary hypothesis is that the difference in the reservoir temperatures and their transients may determine the difference in front velocity between the two cases. In addition, the gravity effects may cause the reservoir temperature differences. The external natural convection through the insulation of the system and internal buoyancy forces on the sodium vapor which, at reservoir temperature, is lighter than the NCG (argon), may heat the reservoir more in the "gravity aided" case. To verify these hypotheses, additional measurements in different gravity orientations, other than the two extreme cases investigated so far, will be performed.

\section{Acknowledgments}

This research was sponsored by NASA Glenn Research Center under Contract No. NNC07QA40P. Lanny Thieme is the technical monitor. We would like to thank Jeff Schreiber and Jim Sanzi of NASA Glenn Research 
Center, and Jaime Reyes and Michael Welz of Lockheed Martin Space Systems Company for helpful discussions about the Stirling system and the VCHP. Tim Wagner was the technician for the program.

\section{References}

${ }^{1}$ Chan, T.S., Wood, J. G. and Schreiber, J. G., "Development of Advanced Stirling Radioisotope Generator for Space Exploration,” NASA Glenn Technical Memorandum NASA/TM-2007-214806, 2007. http://gltrs.grc.nasa.gov/reports/2007/TM2007-214806.pdf.

${ }^{2}$ Anderson, W. G., Tarau, C., "Variable Conductance Heat Pipes for Radioisotope Stirling Systems”, STAIF 2008, Albuquerque, NM, February 10-14, 2008.

${ }^{3}$ Tarau, C., Anderson, W. G., Walker K., "NaK Variable Conductance Heat Pipe for Radioisotope Stirling Systems,” IECEC 2008, Cleveland, OH, July 28-30, 2008.

${ }^{4}$ Tarau, C., Anderson, W. G., Walker K., "High Temperature Variable Conductance Heat Pipe for Radioisotope Stirling Systems,” SPESIF 2009, Huntsville, AL, February 24-26, 2009. 